\title{
Attitudes and evaluative practices: Category vs. item and subjective vs. objective constructions in everyday food assessments
}

\author{
Sally Wiggins* and Jonathan Potter \\ Department of Social Sciences, Loughborough University, UK
}

\begin{abstract}
In social psychology. evaluative expressions have traditionally been understood in terms of their relationship to, and as the expression of, underlying 'attitudes'. In contrast, discursive approaches have started to study evaluative expressions as part of varied social practices, considering what such expressions are doing rather than their relationship to attitudinal objects or other putative mental entities. In this study the latter approach will be used to examine the construction of food and drink evaluations in conversation. The data are taken from a corpus of family mealtimes recorded over a period of months. The aim of this study is to highlight two distinctions that are typically obscured in traditional attitude work ('subjective' vs. 'objective' expressions, category vs. item evaluations). A set of extracts is examined to document the presence of these distinctions in talk that evaluates food and the way they are used and rhetorically developed to perform particular activities (accepting/ refusing food, complimenting the food provider, persuading someone to eat). The analysis suggests that researchers (a) should be aware of the potential significance of these distinctions; (b) should be cautious when treating evaluative terms as broadly equivalent and (c) should be cautious when blurring categories and instances. This analysis raises the broader question of how far evaluative practices may be specific to particular domains, and what this specificity might consist in. It is concluded that research in this area could benefit from starting to focus on the role of evaluations in practices and charting their association with specific topics and objects.
\end{abstract}

Evaluative expressions are a common feature of interaction (Pomerantz, 1984a; Potter, 1998). In using such expressions, people may demonstrate their entitlement to express an opinion, as well as to having particular knowledge about an object or event (Heritage, 2002). Evaluations are not expressed at random points in interaction; they are produced and treated as relevant to ongoing activities. Given how central they are to social activities, it is surprising that evaluations per se have rarely been studied. Social psychology has focused instead upon 'attitudes', as the underlying mental constructs behind evaluations (Eagly \& Chaiken, 1993, 1998). Although the research topic has been underlying mental constructs, the research method has almost invariably been conducted using evaluative words (in scales or questionnaires). The key point is

*Requests for reprints should be addressed to Sally Wiggins, Psychology Division, York House, Nottingham Trent University, Nottingham, NGI 4BU (e-mail: sally.wiggins@ntu.ac.uk). 
that this work has not theorized their status as evaluative words that are in peoples' lexicon for performing actions. In contrast, the current study uses a discursive approach to shift the focus onto evaluative practices in everyday conversation. The aim is to examine the specific, practical use of evaluations and to demonstrate how certain distinctions that are obscured in attitude research methods are important in performing actions.

\section{Discursive psychology, conversation analysis and evaluative practices}

Discursive psychological (DP) approaches have become increasingly familiar in social psychological journals in recent years. Discursive approaches study peoples' social practices. They are typically sensitive to the way discourse is situated (sequentially and rhetorically), to the way it is oriented to performing particular activities, and to how it is both constructed (assembled from words, metaphors, commonplaces and so on) and constructive (bringing particular versions of the world into interaction). They have developed an alternative to the cognitivism of much traditional social psychology, which attempts to explain phenomena in terms of underlying cognitive objects and processes, and instead attempts to describe and explain phenomena in terms of situated discursive practices (Edwards \& Potter, 1992; Potter \& Edwards, 2001, 2003). Hence, analyses of talk enable an examination of how speakers construct their social realities and the business done by these constructions (Edwards, 1997; Potter, 1996b; Wetherell, 2001).

One of the first social psychological topics to be examined by discursive theorists was that of 'attitudes' (Potter \& Wetherell, 1987). The main thrust of this work focused on problems of attitudinal variability, context dependence, and the constitution of the 'attitude object' as an independent entity (e.g. Billig, 1989, 1992; Potter, 1996a, 1998; Potter \& Wetherell, 1987, 1988). The notion of attitudes was itself questioned, and the focus was placed on evaluations and their role in social practices. Discourse studies highlighted the flexible and rhetorical nature of evaluations, which suggested difficulties for the idea that evaluative terms worked primarily as referents of internal states (e.g. Burningham, 1995; Marshall \& Raabe, 1993; Shi-xu, 2000; Verkuyten, 1998). Their emphasis was on practices, and on how evaluations are constructed in talk to perform those practices. However, this research has mostly been limited to interactions taking place in interviews rather than exploring the role of evaluations, in naturalistic materials. Interviews are problematic for studying the practical role of evaluations, as they have their own speech practices and activities, which may involve the direct elicitation of evaluations from interviewees. Analysis of interview material may therefore reveal more about interview practices than about how evaluations are used as part of daily interaction. This suggests that discursive psychologists ought to start to study evaluations in everyday settings. Promoting this suggestion and showing its value is one of the aims of the current paper.

Conversation analysis (CA) has focused on naturalistic materials in a more thoroughgoing way (Hutchby \& Wooffitt, 1998). Here, evaluations have been examined as part of interaction and for their conversational role (e.g. Antaki, 2002; Davidson, 1984; Gardner, 1997; Goodwin, 1986; Goodwin \& Goodwin, 1992; Heritage, 2002; Maynard, 2003; Pomerantz, 1978, 1984a, 1984b). For example, Pomerantz' (1984a) work on second assessments examines the organization and type of evaluative turns that display agreement or disagreement with a prior speaker. Although CA researchers have used naturalistic materials, assessments have typically been treated as a specific, but generic, 
class of terms that allow a speaker to engage in interactional activities. That is, different evaluative words have been considered for their strength (in 'upgrading' or 'downgrading'; Pomerantz, 1984a). Work has also begun to chart distinctions between evaluations according to the objects to which they refer. Most notably, Pomerantz (1978, 1984a) has studied the organization of compliments, noting the way that they are downgraded, returned or reassigned to some other referent as the recipient manages the competing pressures to provide an upgraded second assessment of the referent, but to avoid self praise ('boasting'). Goodwin and Goodwin (1992) also detail the different levels of organization and some of the forms of assessment, as well as some of the kinds of activities that these can be involved in. Maynard (2003) details the different patterns of delivery of good news and bad news depending on the valence of the news and its relationship to the recipient. These studies significantly develop our understanding of the specificities of evaluations; our current work will be building on these studies.

This discussion of work on evaluation in DP and CA has highlighted a need for further work that considers assessments in naturalistic materials and which considers specific evaluative words and their uses. In particular, we will consider the way in which evaluations are delivered as 'subjective' or 'objective' and as referring to categories of things or to individual items.

\section{Attitudes and evaluative terms in traditional social psychology}

We have already made the point that traditional social psychological work on attitudes predominantly uses methods that work with words. We will now flesh that out with an example, and use it to highlight two potential evaluative distinctions that are obscured using such methods. Attitudinal studies typically use rating scales or questionnaires in which people place marks on scales or items that use contrasting words, such as 'good/bad' and 'like/dislike'. Consider an example taken from a study examining the variability of 'attitudes' toward the consumption of wholemeal bread and biscuits (Sparks, Hedderley, \& Shepherd, 1992). It has been chosen because it is food-related, clear and characteristic of this kind of research; it is a high-quality example of the social psychology of attitudes. Our points would apply equally to other high-quality attitude research done within this paradigm. Participants completed a series of rating scales, including the following semantic differentials of their evaluation of the two foods: 'enjoyable-unenjoyable'; 'good-bad'; 'foolish-wise'; 'harmful-beneficial'; 'pleasantunpleasant' (1992, p. 60). The research aim was to assess individual attitudes toward the foods, and to distinguish between the cognitive and affective emphases of these evaluations. These attitudes were then correlated with a rated intention to eat the foods.

From a DP perspective, two problems can immediately be identified. First, the practice of filling out a rating scale may force the participants to make a particular type of evaluation. By selecting the parameters within which foods can be rated (e.g. 'good-bad'), participants are forced into a particular language game of semantic differentials and numerical judgments. This is a specific kind of practice in itself and does not test the possibility that food evaluation in natural situations may be done as parts of very different practices. Moreover, the evaluative terms used are defined by the analyst. Participants' own understandings, orientations and rhetorical reworkings (the kind of thing that DP work has shown to be endemic in everyday interaction) are given little space to emerge and would, anyway, be lost due to the constraints on what is 
recorded as data. There is no space, for example, to negotiate what is understood by the term 'good', or 'enjoy', and how this might be applied to specific foods or eating experiences.

The second problem arises in the interpretation of results. As is standard in attitude research on food, rating scale items and their statistical analyses are interpreted in terms of underlying tastes, food flavours and psychological states. Food 'preferences' and 'attitudes' are typically treated as being the underlying objects behind the evaluative words. ${ }^{1}$ In this way, the words become associated with physical sensations and mental properties. Rating wholemeal bread as 'enjoyable', for example, is treated as characterizing an individual's general sensory experience of eating this food. The concern here is that this interpretation is based almost exclusively on the expression of an evaluation within a set of predefined parameters. Put another way, what is missed is any kind of practice (apart from a putative and conceptually problematic practice of naming inner sensations) that these words might be used for.

These first two problems are familiar in DP commentary on this paradigm of social psychological research. However, we also wish to highlight two specific distinctions that are potentially important in food evaluation, but are obscured in research such as the example discussed above. Their importance has been derived from a mixture of conceptual, theoretical and empirical engagement with a corpus of material involving interactions about food (see also Wiggins, 2002).

\section{Subjective/Objective and Category/ltem}

A distinction can be made between two classes of evaluative terms. Take the following example from Pomerantz' (1978, p. 100) study of assessments.

$\mathrm{K}$ : Those tacos were good!

B: You liked them ...

$\mathrm{K}$ : I loved 'em, yes.

Although $\mathrm{K}$ has offered an evaluation that specifies a quality of the tacos ('good'), B asks $\mathrm{K}$ about his/her feelings toward them (were they 'liked'?). This illustrates that these two things can be, at least on some occasions, treated as different kinds of things. Thus, on the one hand, there are terms that index an individual preference or dislike. Words such as 'like', 'enjoy' and 'love' suggest personal stances or subjective experiences. We will refer to these as subjective evaluations. On the other hand, there are terms that index qualities of the object. Words such as 'good', 'enjoyable' and 'lovely' suggest qualities of objects. We will refer to these as objective evaluations. One way of clarifying this distinction is in terms of a grammatical test that checks whether different terms fit into particular grammatical environments. For example, if the term fits into sentences such as ' $I(x)$ cheese', then it is subjective. Alternatively, if it fits into the sentence 'the cheese is (x)', then it is objective.

It is important to make some observations about this distinction. First, the terms 'subjective' and 'objective' are not intended to carry connotations of correctness or accuracy. They are being used more literally than this: subjective terms index or foreground the subject; objective terms index or foreground the object. They mark something important, but should be used cautiously. Second, there is clearly likely to

'A recent move toward the study of ambivalence in attitudes (e.g. Sparks, Conner, James, Shepherd, \& Povey, 200I; Thompson, Zanna, \& Griffin, 1995) shows a concern with the variability of attitudes toward a particular object. This area of research, however, retains a mentalistic notion of attitude that is considered to be independent of the evaluative terms themselves. 
be a close relationship between a subjective evaluation such as 'love' and an objective evaluation such as 'lovely'. To highlight the distinction is not to deny the relationship. Nevertheless, the existence of a grammatical marking of the difference between 'love' and 'lovely' suggests that it may be available for performing different functions.

The second distinction to be made is between evaluations of categories and evaluations of specific items. This is the kind of distinction that Billig $(1985,1996)$ has shown to be crucial for understanding argumentation about race and social categories. However, we are here focusing it on food evaluations. For example, is the evaluation of a specific item, or is it an evaluation of a category or class of things that this item is a member of. Such distinctions are marked in conversation in various ways-for example, grammatical differences such as 'I like cheese' or 'I like this cheese' may be used. Various levels of categorization and particularization are possible in evaluative talk of this kind. This distinction is something that Goodwin and Goodwin (1992, p. 165) have briefly noted, though we focus on it here as having particular interactional consequences in evaluation talk.

It may be possible to mark some distinctions of this kind in traditional attitude measures. However, methods of measurement typically obscure them. On the one hand, if participants are presented with food to taste and asked to rate on it on a scale, this does not distinguish ratings of this specific food item or the class that it comes from. On the other hand, if they are asked to rate food through a verbal categorization, then this too will not make it clear whether they are rating either a category of food (e.g. through the invocation of some kind of prototype) or a specific example (e.g. the last instance they remember).

Our point in highlighting these two distinctions is not to attempt to refine traditional attitude measurement. Rather, the existence of these distinctions highlights the possibility of particular evaluative practices. It is these that will be the focus of this paper.

\section{Issues in food evaluation}

In this paper we develop an empirical study of food evaluations in natural interaction. This builds on the limitations noted with existing work in discursive psychology and conversation analysis. That is, it considers naturalistic (rather than interview) interaction and makes further distinctions between different kinds of assessments and their role in a specific domain. In addition, the focus on natural interaction moves it beyond traditional attitude measures.

The particular focus of the study, then, is on the two distinctions:

- Subjective vs. objective

- Category vs. item.

The aim is, first, to document the existence of these distinctions in practice and, second, to start to show some of the business that these distinctions allow in actual interaction. More generally, we will be considering the different concerns and accountabilities that arise when using different evaluative expressions. For example, do references to personal taste or food quality become bound up with the management of eating practices such as complimenting, avoiding disagreement, and so on?

\section{Method}

The participants and their mealtimes

The data for this study are taken from a corpus of family mealtime conversations. Ten families were recruited via personal contacts to record their meals on a regular basis. 
The criteria for selecting the families were that they included at least one child, and routinely shared mealtimes. Pilot research indicated that families with children were more likely to eat together frequently than were non-family adult groups. Since they regularly ate together, participation did not require any change to household routines. This is a key aspect of the research, and provides the basis for a more 'naturalistic' study than conventional designs (Wiggins, Potter, \& Wildsmith, 2001).

The participants were asked to self-record their meals as regularly as convenient, using audio equipment provided by the researcher. This was carried out over a period between 4 and 12 weeks. The total data corpus consisted of 86 mealtimes, spanning 40 hours of recorded conversation. All names and identifying details have been disguised.

\section{Transcription}

The audiotapes were initially transcribed to first-pass (words only) standard. Then all sections that included talk relevant to food or eating were fully transcribed. The transcription system used was that developed by Gail Jefferson (Jefferson, 1984; see also Hutchby \& Wooffitt, 1998). This highlights features of speech delivery as well as emphases, intonation and sequential detail (see Appendix for a key to notation).

\section{Analytic procedure}

Discursive approaches emphasize the construction and action-orientation of talk in interaction (Wetherell, 2001). Discourse is understood in terms of the particular activities it performs, such as complaining, persuading others, and making offers of food. In this analysis we have collected together examples to illustrate the use of subjective and objective evaluations and the sorts of practices that this distinction operates in. We will note the way the category/item distinction is used or not in these first extracts and then go on to examine a small collection of examples to examine the operation of this distinction.

These extracts are closely examined with the aim of explicating the activities they are part of. In common with methods of discursive psychology, the analysis will focus on: the sequential placing of evaluations in the extracts; how the evaluations are oriented to by other speakers; the way the detail of what is said contributes to the activity; and the material reproduced will allow the reader to assess the interpretations offered (Horton-Salway, 2001; Potter, 2003, in press). However, it is not intended as a complete analysis; rather it should identify and highlight phenomena that have not previously been subjected to empirical study and point the way toward further analysis.

\section{Analysis}

\section{Subjective vs. objective evaluations}

The analysis begins by considering extracts that involve evaluations that are 'subjective' or 'objective'. We will document their existence and some of their features.

First a subjective evaluation; that is, one that satisfies the grammatical test of taking the form 'I (x) food'. Sandra (the mother of the family) talks through her plans for the 
following day as the family eat their evening meal (note that the code at the start is simply a unique identifier for tape and transcript position).

(I) SKW/KIa-MI (48-53) Subjective evaluation

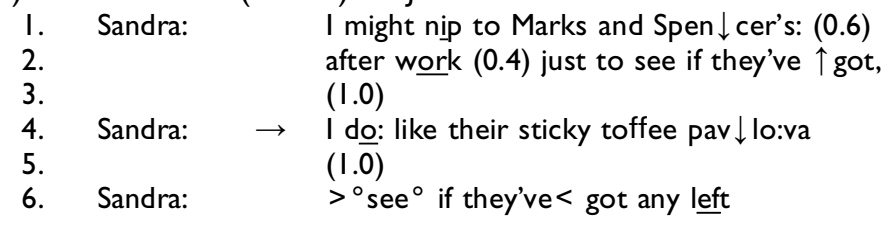

In line 4 Sandra produces a subjective evaluation. The 'I do: like' specifies a personal or subjective preference. The food is named, without ascribing any particular qualities to it. The preference is marked as the speaker's own, without indicating whether other speakers present do or should have the same preference.

Note the organization of the talk here. The speaker starts by outlining a potential course of action (going to Marks and Spencers-a UK department store noted for its food). She starts to describe the reason 'to see if they've got', but then self-repairs with the evaluation. The subjective evaluation thus serves as an account for this (future) course of action. In particular, it justifies going to Marks and Spencers rather than another, perhaps more convenient, cheaper, or more routinely visited store. If there is a chance that there may be pavlova left (line 6), and this is something that Sandra shows herself to particularly like, it makes the 'nipping' to Marks and Spencer all the more reasonable. The term 'nipping' itself helps make the action seem simple and unproblematic. The general and simple point, then, is that subjective evaluations can be used as accounts for actions.

The next example includes an 'objective evaluation'; that is, one that satisfies the

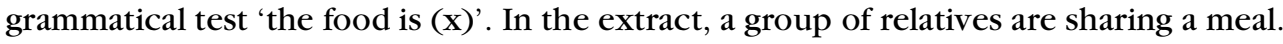
Laura (the mother) has cooked and served the dinner.

(2) SKW/G2a-M8 (93-99) Objective evaluation

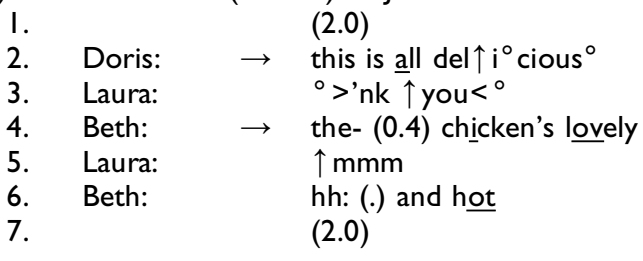

In line 2 Doris produces an 'objective' evaluation, as does Beth in line 4 . In each case the evaluation specifies features of the food ('delicious', 'lovely'). Note the difference from Extract 1, in this case the objective evaluation suggests that these are features of the food itself rather than (possibly) ideosyncratic to the speaker.

As with Extract 1, the sequential information allows us to understand the activity that the evaluations are part of. Note the 'thank you' from Laura in line 3. She is responding to Doris' evaluation as a compliment and doing one form of compliment receipt (Pomerantz, 1978, 1984a). That is, the assessable quality of the food is treated as a consequence of Laura's actions. Again, the evaluation is doing more than making an abstract formulation of quality, it is performing a specific action; in this case making a compliment. 
Why might we see different forms of evaluation, subjective and objective? A preliminary possibility is that the subjective assessment in Extract 1 accounts for an individual's action in shopping for a particular dessert. One of the features provided by the subjective nature of the evaluation is to present the activity as a personal choice-she does not implicate others in the evaluation, and therefore in any way pressure them toward this course of action. In contrast, to make a compliment, as we see in Extract 2, the objective evaluation presents the judgment as more than a personal one, and therefore makes a stronger compliment. Put another way, if a speaker gives a subjective evaluation, they may project the possibility that others might not like the food, and therefore weaken the compliment.

Let us develop these possibilities by considering some slightly more complex examples. In the following extract, Beth is requesting some wine. As is made clear elsewhere in the material, Beth is 11 years old; Laura is her mother; Bill is her uncle.

(3) SKW/G2a-M8 (740-749) Subjective and objective evaluations

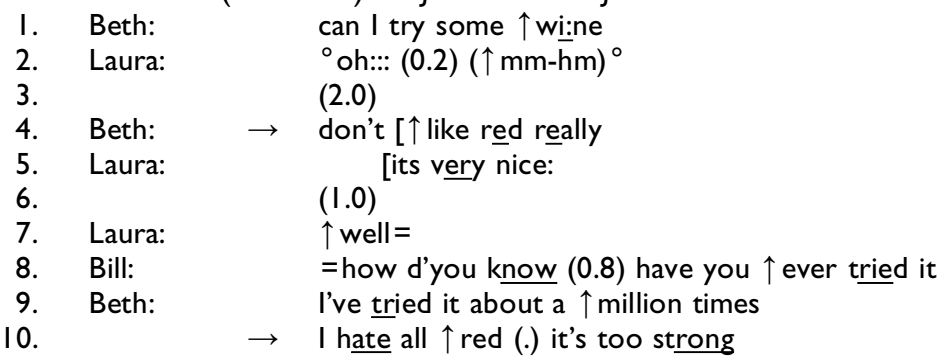

There is a lot of complexity in this extract, and some uncertainty that comes from working with an audio record rather than a full video. Nevertheless, it illustrates some features about the practical role of subjective as opposed to objective evaluations.

The initial thing to note is that the sequence is occasioned by Beth's request to 'try some wine' (line 1). In couching her request in this way she both attends to her 'junior' status as someone who needs permission and also indicates that her drinking will be somewhat experimental (through the use of the term 'try' rather than 'have'). Laura's elaborate receipting (the extended 'oh' and delay in line 2) displays her subsequent agreement as considered. We do not know precisely what happens in the two seconds that follow this. However, there is good reason to think that Laura has reached for, or started to pour red wine (with white as another option). ${ }^{2}$ This suggests that Beth's subjective evaluation in line 4 is doing a refusal. That is, formulating a negative evaluation is used to turn down the offer of red wine.

Three points are worth highlighting here. First, we see an assessment being used to perform an activity. That is, we see in this everyday setting that peoples' evaluative language is practical rather than abstract or theoretical. We are here highlighting two levels at which the practical/theoretical contrast operates. On the one hand, at the level of theory it highlights an approach to language influenced by linguistic philosophy and ethnomethodology that considers what words are doing in particular practices rather than privileging their putative referential role. On the other, at the level of methodology it highlights the value of studying words in their natural contexts of use

\footnotetext{
${ }^{2}$ Note the alternative idea that Beth has been given and tried it in the period is very unlikely, not just from the timing but because it makes Laura's line 5, and particularly Bill's line 8, anomalous.
} 
rather than the heavily constrained universe of rating scales and other attitude measures.

Second, we can start to understand a bit more the interactional value of using subjective assessments. By constructing her assessment as a personal or subjective one Beth is orienting to red wine as a familiar drink, one that is on the table and that others are drinking. That is, she is avoiding conflict about the quality of wine itself, or questioning the judgment or tastes of the others present. This construction focuses the accountability for not drinking the red on herself rather than on others for drinking it.

The third thing to note about subjective assessments is something pointed out by philosophers of language such as Wittgenstein (1953). The language game of avowals of this kind (pain, desire, taste sensations) treats them as directly felt and privileged. The speaker does not have to make inferences about such things, nor do they require evidence. Neither are they directly open to dispute by other speakers. However, what we see in the extract above is something interesting. Although Laura does not directly contest Beth's subjective evaluation, she does offer a contrasting objective evaluation. One way of considering this is that speakers may draw on the rhetorical effectiveness of the language game of sensation when, for example, turning down food, but there are also rhetorical counters than can be used against them. Such rhetorical patterns seem to be characteristic of food talk between parents and children (see examples in Wiggins, 2001; Wiggins et al., 2001).

Now let us consider some of the complexities about using evaluations in talk. In partial overlap in line 5 Laura does a strong objective evaluation of the red wine (note the emphasized 'very' and the extended 'nice'). One way of considering this is as an attempt to persuade. Emphasizing the objectively positive quality of the wine after the refusal provides an opportunity for Beth to reconsider. There is nothing verbal here, although the silence (line 6) and further questioning (note the rising intonation on 'well' in line 7) suggest that Beth may be displaying some kind of equivocation.

The general point to observe here is the way that subjective and objective evaluations are used to do different things. By presenting the niceness as a quality in the wine, Laura encourages Beth to try it; by presenting her dislike as a personal judgment, Beth turns it down without disputing another's choices. (We will just observe here, without following it up, that there are some interesting issues of asymmetry-of categories and descriptions-highlighted in lines 4 and 5. Laura's objective evaluation in line 5 may be heard as questioning the judgment or the basis of the judgment of Beth's subjective evaluation in line 4. Such questioning of another person's subjective evaluations might be related to features of parent-child relationships.)

Another notable feature of evaluations in the extract is what happens in lines 8-10. Bill, like Laura, questions Beth's subjective assessment. In this case, however, he asks about the grounds for her assessment: how does she know she doesn't like it, has she ever tried it? Having had her evaluation in line 4 doubted by her mother and uncle, Beth provides a very emphatic formulation of the evidence she is working with; she has tried it 'a million times'. This is followed by an upgraded and extreme form assessment: from 'not liking red really' she moves to 'I hate all red', with emphasis on the 'hate' (Edwards, 2000; Pomerantz, 1986). And this in turn is followed by a description of a negative quality of the wine: it is 'too strong'. The notable thing for us here is the way the subjective assessment is presented as grounded in evidence; she has tried the wine and she can specify a particular negative quality that she does not like. This negative quality of the wine makes her assessment accountable. It is important to hold in mind, however, that this disagreement about the quality of wine is occasioned by 
her refusal of the red. Her position is not abstract, but has the practical upshot of not being given the red to drink.

Let us consider one further example to explore the practical roles of objective and subjective assessments. Extract 4 comes from near the end of the meal that appears in Extracts 2 and 3. As is clear, Laura has cooked the food and is treated as the food provider. Bill is in the midst of a previous discussion, which he continues throughout this extract.

(4) SKW/G2a-M8 (3 I5-322) Subjective and objective evaluations

$\begin{array}{llll}\text { I. } & \text { Doris: } & \rightarrow & \text { that was lovely Lau: } \downarrow \text { ra [thank } \downarrow \text { yo:u } \\ \text { 2. } & \text { Bill: } & & \text { [because eh- } \\ \text { 3. } & \text { Beth: } & \rightarrow & \text { it is }[\text { love } \downarrow \text { ly } \\ \text { 4. } & \text { Laura: } & \rightarrow & \quad[>\text { did you enjoy that }<\text { there is } \\ \text { 5. } & & \text { [some }>\text { d'you want }< \\ \text { 6. } & \text { Bill: } & & \text { [she } \uparrow \text { said- } \\ \text { 7. } & \text { Laura: } & \text { there's a bit mo:re if you } \downarrow \text { want }(0.6)>\text { there's } \\ \text { 8. } & & \text { a bit }<\text { more }[\uparrow \text { sauce? }\end{array}$

In line 1 we see Doris praising Laura for the 'lovely' meal, and thanking her. Beth immediately follows with her own evaluation. Note that both evaluations are objective. They describe the meal as lovely rather than characterizing themselves as, say, having loved it. Both these assessments work as compliments of Laura. As Pomerantz (1978) has shown, compliments can be tricky to receive as there is a conflict between agreeing with the assessment on the one hand, and avoiding self-praise (boasting), on the other. Often compliments are reassigned to a different referent or downgraded in order to manage this tension. Now, note the way that Laura does not agree with the evaluation of the food using another objective description ('yes, it was, wasn't it', say, which might have sounded boastful), rather she reformulates the objective description in subjective terms, as them enjoying the food. Another feature of her management of their compliment is to treat it as a potential request for more food. Thus she responds to the positive evaluation by offering more.

In this example, then, we see objective evaluations treated as both compliments and potential requests for more food. That is, they have a practical role in the interaction.

\section{Category vs. item evaluations}

In this second analytic section we will consider the way that the contrast between evaluations of a category of food and a specific food item may operate. This is not a simple distinction as different levels of categorization and particularization may be available. Let us start with a simple example to illustrate how categorizations and particularizations may relate to evaluations.

(5) SKW/D2a-M3 (I I 05-I I I 7) Category and item

I. Anna: $\rightarrow$ I'm not quite sur:e I $\uparrow$ like this mincemeat $(0.4)$

2. $\quad I \uparrow$ like it: $(0.6)$ but its (.) too far removed from

3.

4. Jenny:

5. traditional (0.2) [isn't $\downarrow$ it

6. Michael: $\rightarrow \quad \mathrm{I}$ 'm $\uparrow$ never really $\uparrow$ kee:n on traditional mincemeat

7. Anna: no?

$8 . \quad(0.4)$

9. Michael: $\rightarrow \quad \mid \downarrow$ like that more than I do the traditional 
10. Anna:

II.

12. Jenny:

$\underline{\mathrm{mmm}}$

13.

$(0.6)$

${ }^{\circ} \mathrm{mmm}^{\circ}$

(2.0)

The first thing to note about this extract is Anna's evaluation in line 1. Its grammatical construction identifies a particular food, 'this mincemeat'. She contrasts it with a category of mincemeat she calls 'traditional'. Note the way this is not just an abstract contrast; by invoking the food's difference from 'traditional mincemeat' she accounts for her dislike.

The second thing to note is the way these constructions can manage one of the features that arise with assessments. Pomerantz (1984a) has shown that there is a strong normative expectation for assessments to be followed by second assessments. One of the features of subjective evaluations of this kind is that they manage the potential disagreement between assessments. We can see this here in the construction of Michael's turn in line 6. Although he is offering a contrasting assessment of traditional mincemeat it is not prefaced by the kind of dispreference markers we might expect for a disagreeing second assessment. Compare Extract 5 above with the following:

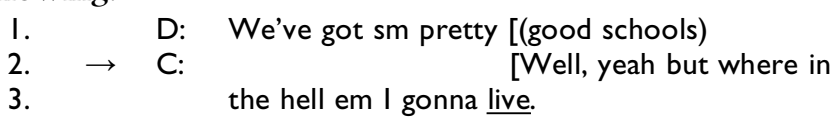

(from Pomerantz, 1984a, p. 72)

In the dispreferred second assessment here we see characteristic features such as a 'well' preface and an agreement inserted prior to the disagreement. In line 6 of Extract 5 Michael's assessment is done without a 'well' preface, and with the assessing component produced emphatically ('never really keen') and early in the turn. While the 2.4-second pause on line 5 might be taken to signal disagreement, it is much more characteristic of interaction during eating, where it may equally (and visibly) signal that speech construction is being constrained by chewing. But constructing the evaluation as a subjective one, a different kind of accountability is projected. ${ }^{3}$

To illustrate some of the rhetorical possibilities in using categories vs. item evaluations, we will examine the following relatively simple example. Extract 6 comes from near the end of a family meal; Lesley is Chris's mother.

(6) SKW/J Ib-M3 (44I-448) Category and item

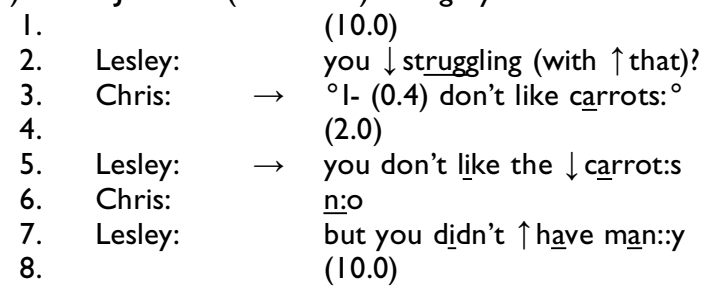

When Lesley asks her son if he is 'struggling' with his food, his response is constructed as a subjective evaluation. That is, he accounts for his non-eating by indicating

\footnotetext{
${ }^{3}$ The subjective/objective distinction raises some interesting questions about preference markers and second assessments. For instance, it would be interesting to consider whether using a subjective evaluation precludes the need for a dispreference marker, given that the evaluation may not directly challenge that of another speaker. Work on this topic is currently being undertaken by the authors of this paper.
} 
his personal evaluation. Looked at another way, this shows again how a subjective evaluation can act as an account for an action. What we wish to focus on now, however, is the construction of the evaluation as a category. Contrast Chris's 'I don't like carrots' (line 3) with Lesley's 'you don't like the carrots' (line 5). The difference may seem subtle in the abstract, but the contrast has practical upshots. In particular, by saying he 'does not like carrots' (category) Chris provides a general account for not eating them, which does not require him to eat any to confirm this, and might suggest that the problem is his mother not knowing, or ignoring, his established preference (this latter problem may occasion his mother noting that he did not have many to start with, presumably served by her). In contrast, Lesley's formulation about him not liking 'the carrots' (item, emphasis added for clarity) suggests a judgment about these specific carrots; that is, a judgment that would require him eating at least some to warrant.

Again, in practical terms we can see the way the two different kinds of evaluation are used to perform two different practical tasks (roughly avoiding carrot-eating and encouraging carrot-eating).

Now we have explicated some of the possibilities in using category vs. item evaluations, we can reconsider the earlier extracts to highlight the relevance of the category or item constructions. We will now return to the previous extracts (1-4 inclusive) and refer to these as $1 b, 2 b$, and so on. In Extract $1 b$, below, we see Sandra using a particularized evaluation in line 4 .

(Ib) SKW/KIa-MI (48-53): Item evaluation
I. Sandra:
I might nip to Marks and Spen $\downarrow$ cer's: (0.6)
2. after work (0.4) just to see if they’ve $\uparrow$ got,
$3 . \quad(1.0)$
4. Sandra: $\rightarrow \quad$ I do: like their sticky toffee pav $\downarrow$ lo:va
$5 . \quad(1.0)$
6. Sandra: $\quad>{ }^{\circ}$ see $^{\circ}$ if they've $<$ got any left

Our interest is in how the item evaluation 'their sticky toffee pavlova' contributes to the action. In this case the evaluation is working as an account for going to a particular store. Using an item evaluation justifies the specificity of the trip. For example, it heads off potential suggestions of other convenient shops that might have pavlova, or even sticky toffee pavlova. The item evaluation acts as a simple justification here.

Extract $2 \mathrm{~b}$ also shows a simple use of item evaluations.

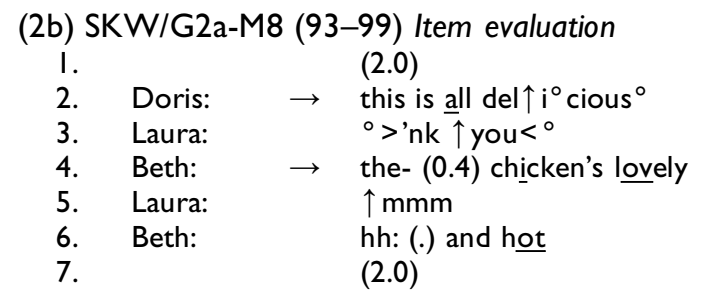

The item evaluation is part of what makes the assessments work as compliments. For example, if Beth claimed to like chicken as a category it would undermine the specific compliment of Laura's cooking. It would suggest merely that Laura has made a good judgment in choosing to cook chicken. Doris' combination of an item assessment ('this') with a reference to the whole meal ('all') is an effective way of highlighting cooking skill over the quality of any particular food. 
Extract $3 \mathrm{~b}$ shows some ways in which category and item assessments contribute to performing actions.

(3b) SKW/G2a-M8 (740-749) Category and item

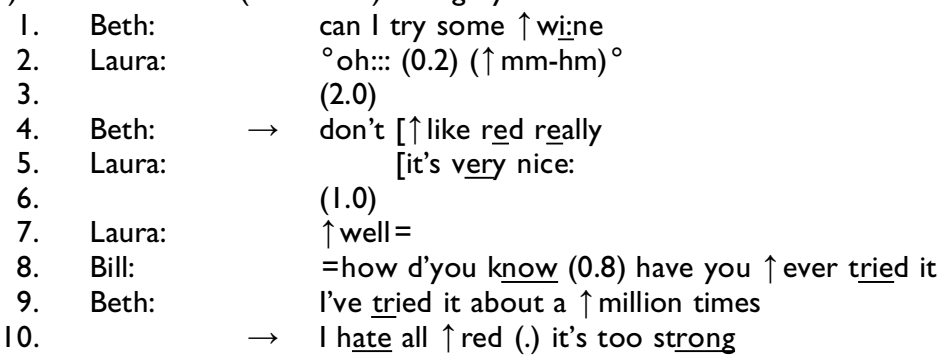

Note the way Beth's evaluation in line 4 is a category evaluation; it is not this red wine, but red wine as a general category. This justifies her rejection without needing to try this particular wine. By assessing the category as a whole, trying this one is not required. In contrast, Laura's turn in line 5 is an item evaluation (there is a little ambiguity, but the sequential positioning of 'it's' before Beth has said 'red wine' supports this interpretation). Its assessment is of the particular wine that is being offered.

In Beth's next turn (lines 9 and 10) her construction orients to the possibility of different reds having different qualities (and therefore the possibility that she is acting in a prejudiced fashion). Not only has she tried red wine 'a million times', but she hates 'all' red wine. Moreover the negative feature she offers to justify her assessment ('too strong') is something that could be applied to red wines as a class.

Finally, we will reconsider Extract $4 \mathrm{~b}$. This is another simple example where item assessments are used in compliments.

(4b) SKW/G2a-M8 (3 I 5-322) Item evaluation

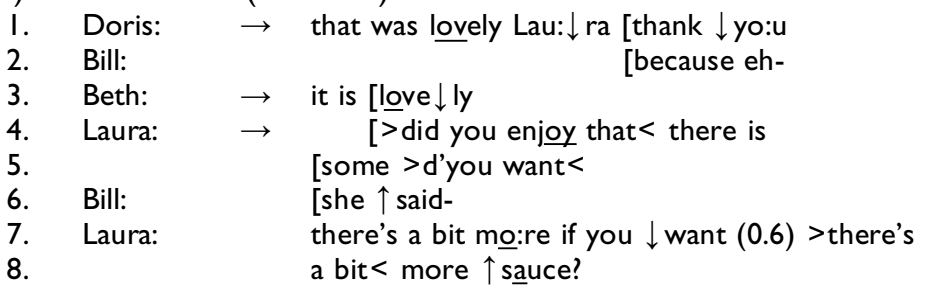

Note the way that both Doris and Beth construct their compliments as item assessments (lines 1 and 3). Again, item assessments emphasize the specific production of the food rather than its generic quality.

\section{Discussion}

Let us start by summarizing our observations about the action orientation of food evaluations. In the extracts above we have identified the practical role of evaluations in a number of activities:

- Justifying/accounting for a future food-related activity (Extract 1).

- Complimenting the cook or provider of food (Extracts 2 and 4). 
- Persuading someone to eat/drink (Extract 3).

- Refusing food/drink and accounting for that refusal (Extracts 3 and 6).

- Requesting more food/drink (Extract 4).

As well as this broad pattern of evaluations being oriented to action, the analysis highlights a range of specific uses of subjective or objective evaluations, and category or item evaluations. For example, we have shown the way subjective evaluations can be used in a number of actions.

- Subjective evaluations can manage the implications for co-conversationalists of evaluation. For example, an assessment of food can be made while limiting the suggestion that other speakers need to respond to it or agree with it (Extract 1).

- Subjective evaluations can be used to account for the specific speaker engaging in specific activities. By constructing an activity as occasioned by a subjective evaluation, other people are not implicated in that activity (Extract 1).

- Subjective evaluations can be used in food refusals. The 'logic' of subjective assessments provides a privileged resource for making refusal accountable (Extracts 3 and 6).

Objective evaluations also have a range of uses.

- They may be used in compliments, avoiding the caution that may be displayed in subjective evaluations (Extracts 2 and 4).

- They may be used in persuasive talk, particularly when countering subjective evaluations (Extract 3).

We have also highlighted the practical importance of the category/item distinction. Let us start by summarizing some uses of item evaluations.

- Item evaluations may be used to limit the general implications of an assessment, to allow a different evaluation of the general category (Extract 5).

- Item evaluations may be used to manage rhetorical conflict by formulating a specific like or dislike rather than a general category dislike (Extracts 3 and 6).

- Item evaluations may justify particular actions that relate to particular category members rather than the category as a whole (Extract 1).

- Item evaluations may be used to make compliments specifically directed (Extracts 2 and 4$)$.

Finally, category evaluations also have a range of uses.

- They may be used to turn down offered food or drink without required direct knowledge of the specific food or drink (Extracts 3 and 6).

- They may be used to establish a preference as enduring over time rather than related to just the occasion at hand (Extracts 3 and 6).

This is not offered as an exhaustive list. The aim is to provide sufficient analytic detail to document some general claims.

First, the analysis has established that evaluative talk in everyday settings is embedded in, and contributes to, a range of different practices. This does not in itself show that these participants cannot, and do not, use evaluations in a more abstract manner. However, it casts doubt on any assumption that evaluative talk about food has an abstract or disinterested nature, like the talk in a focus group or the language used when filling in attitude scales. 
Second, the analysis has established that the two distinctions ignored or obscured in traditional attitudes measures are important in practical settings where food evaluations are being used. Constructing evaluations as subjective or objective may be crucial in the particular action that is performed, and yet evaluative terms that mark this distinction (e.g. like, good) are commonly used together in attitude measures. Constructing evaluations as applying to categories of things or specific items or instances may also be crucial in performing the action; yet traditional methods often fail to mark this distinction.

We are not suggesting that these are the only interactionally relevant distinctions between different classes of assessments or forms of evaluative language. One theme we have not developed here is the possibility that asymmetries of knowledge, say, or status may be relevant to how speakers construct evaluations. For example, take this extract from Pomerantz (1978, p. 84).

A: Well I- I wannid to say I enjoyed your class so this morning, and too.

B: Well, thank you.

If this followed the pattern of the food evaluations documented above, we might think that an objective evaluation (e.g. 'your class was excellent') would be a better compliment than the subjective form 'I enjoyed your class'. However, it may well be in this example that an objective evaluation made by a student to the teacher would claim an epistemic authority that might be considered disrespectful or presumptuous, hence the subjective form (cf. Heritage \& Raymond, 2002). In addition, it might be relevant to distinguish food as a mass (e.g. an amount of cheese) from food as a number (e.g. more cheeses). ${ }^{4}$ Other possibilities will no doubt be revealed by further conceptual and analytic work.

Furthermore, although as analysts we have highlighted the importance of these distinctions, we are not claiming that people do not on occasion, and for a range of potential reasons, construct evaluations in a manner that blurs the distinctions together, or use one form next to another form. Again, consider this example from Pomerantz (1978, p. 85):

A: Why it's the loveliest record I ever heard.

B: Well thank you.

Although 'lovely' would be classed as an objective assessment using our grammatical test, the construction of a personal ranking in which it figures makes it considerably more subjective. It may be that the positioning of objective and subjective together like this helps the construction of the extremely positive evaluation.

What are the consequences for traditional attitude research? This is a complex question. Attitude researchers might argue that there is a long history to such research, and where appropriate care is taken with the construction of items, and appropriate caution about the inferences made, the results can be predictive (Eagly \& Chaiken, 1993). Indeed, they might point to a concern with specificity that drove many developments, such as Ajzen's (1988) theory of planned behaviour, and note the parallel with the significance of item vs. category evaluations we see in our analysis. However, our analysis highlights a gulf between the way that evaluative talk about food is treated in social psychology and how it is treated in everyday settings (at least some of the time, for some people). Indeed, it might be argued that the appropriate research start-point

${ }^{4}$ We are grateful for an anonymous referee for highlighting the potential relevance of this distinction. 
for understanding evaluations should be the everyday ecology of practices that people engage in rather than the abstract, theoretical practice required for people to use attitude scales. And it may be that some, or even many, of the well-known difficulties in predicting 'behaviour' from attitude measures may be a consequence of blurring the basic distinctions between subjective and objective, and category and item evaluations. Or it may be a consequence of failing simply to grasp what evaluative talk does in its home environment. Nevertheless, for the rather different enterprise of attitude researchers, it may be that closer attention to these distinctions may be an aid to question construction.

We cannot establish an alternative account of evaluations focused on discourse practices from a single analysis of this kind, but we can start to make a plausible case. After all, readers of this article will all be experienced and recurrent eaters and we doubt that they will find the extracts odd or unusual. What we have highlighted are recognizably commonplace features of eating and interaction. It is only now that we have the procedures for recording, analysing and showing their wider significance.

A critique of attitude methods and assumptions is only part of the aim of this article. More important is our wish to open up the topic of evaluative practices in the domain of food and drink for study. We have shown the role of evaluations in some practices but there is much more to be done. For example, how are particular practices related to issues to do with relationships, asymmetry between persons (parent/child, etc.), the providing and cooking of food, the relation of assessments and compliments, and so on?

The study also starts to raises two broader questions. First, it poses the question of how specific the practices documented here are to the domain of food and drink. That is, are evaluative practices unique to, or especially associated with, certain domains? Or is it that there are more basic practices (e.g. complimenting) which are generic and cut across domains. This is a topic that needs following up. However, it seems likely that there may be special characteristics associated with taste sensations. We noted above that claims about food preference were not directly disagreed with, although we also saw indirect disagreements (Extracts 3 and 6). Eating can also be an accountable issue, by which speakers may be held to account for their evaluations in relation to previously expressed preferences. The taste of food may be constructed as an individual experience, thus making it hard for others to claim access to the sensation. In this way, speakers manage issues such as taste and food preferences, and the organization of these practices (and the accompanying uses of food and drink evaluation) may be specific to this domain.

Second, it raises issues about the relation of work on evaluative practices of this kind to other areas in social psychology where assessments are found. For instance, it could contribute to research on prejudice, racism and discrimination. We noted above how issues of categorization and particularization were often critical to the performing of particular actions. This relates both to traditional social psychological work on categorization and their consequences (raising further problems for cognitivist interpretations of the effect of categorization-see various papers in Antaki \& Widdicombe, 1998) and contributes to discursive and rhetorical work on rhetorical features of racism, sexism and so on (e.g. Billig, 1985, 1999; Edwards, 1998; Gill, 1993; LeCouteur, Rapley, \& Augoustinos, 2001; Wetherell \& Potter, 1992). For example, how far do people use objectively constructed assessments when producing negative descriptions of minority groups? On what occasions do people move to subjectively constructed assessments for producing such descriptions? Social psychological work on food 
preferences, racism, sexism and so on is likely to benefit from a better understanding of the way in which evaluative practices are organized, generated, undermined and used in natural settings.

\section{Acknowledgements}

The authors would like to thank Anita Pomerantz for thoughtful and critical comments on an earlier version of this paper, as well as Margaret Wetherell as editor and two anonymous referees for the BJSP for further helpful comments.

\section{References}

Ajzen, I. (1988). Attitudes, personality and behaviour. Milton Keynes: Open University Press.

Antaki, C. (2002). Question design to avoid invoking the interviewee's identity as an impaired person. Paper presented at the International Conference on Conversation Analysis, University of Copenhagen, 17-21 May.

Antaki, C., \& Widdicombe, S. (Eds.) (1998). Identities in talk. London: Sage.

Billig, M. (1985). Prejudice, categorization and particularization: From a perceptual to a rhetorical approach. European Journal of Social Psychology, 15, 79-103.

Billig, M. (1989). The argumentative nature of holding strong views: A case study. European Journal of Social Psychology, 19, 203-223.

Billig, M. (1992). Talking of the royal family. London: Routledge.

Billig, M. (1996). Arguing and thinking: A rbetorical approach to social psychology (2nd ed.). Cambridge: Cambridge University Press.

Billig, M. (1999). Freudian repression: Conversation creating the unconscious. Cambridge: Cambridge University Press.

Burningham, K. (1995). Attitudes, accounts and impact assessment. Sociological Review, 43 (1), 100-122.

Davidson, J. (1984). Subsequent versions of invitations, offers, requests or proposals dealing with potential or actual rejection. In J. M. Atkinson \& J. Heritage (Eds.), Structures of social action: Studies in conversation analysis. Cambridge: Cambridge University Press.

Eagly, A. H., \& Chaiken, S. (1993). The psychology of attitudes. New York: Harcourt Brace Jovanovich.

Eagly, A. H., \& Chaiken, S. (1998). Attitude structure and function. In D. T. Gilbert, S. T. Fiske, \& G. Lindzey (Eds.), The handbook of social psychology (Vol. I, 4th ed., pp. 269-322). New York: McGraw-Hill.

Edwards, D. (1997). Discourse and cognition. London: Sage.

Edwards, D. (1998). Analysing racial discourse: A view from discursive psychology. In H. Van den Berg, H. Houtcoup, \& M. Wetherell (Eds), Analyzing interviews on racial issues: Multidisciplinary approaches to interview discourse. Cambridge: Cambridge University Press.

Edwards, D. (2000). Extreme case formulations: Softeners, investment and doing non-literal. Research on Language and Social Interaction, 33(4), 347-373.

Edwards, D., \& Potter, J. (1992). Discursive psychology. London: Sage.

Gardner, R. (1997). The conversation object mm: A weak and variable acknowledging token. Research on Language and Social Interaction, 30(2), 131-156.

Gill, R. (1993). Justifying injustice: Broadcasters' accounts on inequality in radio. In E. Burman \& I. Parker (Eds.), Discourse analytic research: Repertoires and readings of texts in action (pp. 75-93). London: Routledge.

Goodwin, C. (1986). Between and within: Alternative sequential treatments of continuers and assessments. Human Studies, 9, 205-217. 
Goodwin, C., \& Goodwin, M. H. (1992). Assessments and the construction of context: Language. In A. Duranti \& C. Goodwin (Eds.). Rethinking context: Language as an interactive phenomenon. Cambridge: Cambridge University Press.

Heritage, J. (2002). Oh-prefaced responses to assessments: A method of modifying agreement/ disagreement. In C. Ford, B. Fox, \& S. Thompson (Eds.), The language of turn and sequence (pp. 196-224). New York: Oxford University Press.

Heritage, J., \& Raymond, G. (2002). The terms of agreement: Indexing epistemic authority and subordination in talk-in-interaction. Paper presented at the International Conference on Conversation Analysis, University of Copenhagen, 17-21 May.

Horton-Salway, M. (2001). The construction of M.E.: The discursive action model. In M. Wetherell, S. Taylor, \& S. J. Yates (Eds). Discourse as data: A guide for analysis (pp. 147-188). London: Sage.

Hutchby, I., \& Wooffitt, R. (1998). Conversation analysis: Principles, practices and applications. Cambridge: Polity.

Jefferson, G. (1984). Transcript notation. In J. M. Atkinson \& J. Heritage (Eds.), Structures of social action: Studies in conversation analysis (pp. ix-xvi). Cambridge: Cambridge University Press.

LeCouteur, A., Rapley, M., \& Augoustinos, M. (2001). 'This very difficult debate about Wik': Stake, voice and the management of category memberships in race politics. British Journal of Social Psychology, 40, 35-58.

Marshall, H., \& Raabe, B. (1993). Political discourse: Talking about nationalization and privatization. In E. Burman \& I. Parker (Eds.), Discourse analytic research: Repertoires and readings of texts in action (pp. 35-51). London: Routledge.

Maynard, D. (2003). Bad news, good news: Conversational order in everyday talk and clinical settings. Chicago: University of Chicago Press.

Pomerantz, A. (1978). Compliment responses: Notes on the co-operation of multiple constraints. In J. Schenkein (Ed.), Studies in the organisation of conversational interaction (pp. 79-112). New York: Academic Press.

Pomerantz, A. (1984a). Agreeing and disagreeing with assessments: Some features of preferred/ dispreferred turn shapes. In J. M. Atkinson \& J. Heritage (Eds) Structures of social action: Studies in conversation analysis (pp. 57-101). Cambridge: Cambridge University Press.

Pomerantz, A. (1984b). Giving a source or basis: The practice in conversation or telling 'how I know'. Journal of Pragmatics, 8, 607-625.

Pomerantz, A. (1986). Extreme case formulations: A way of legitimizing claims. Human Studies, 9, 219-229.

Potter, J. (1996a). Attitudes, social representations and discursive psychology. In M. Wetherell (Ed.), Identities, groups and social issues (pp. 119-174). London: Sage.

Potter, J. (1996b). Representing reality: Discourse, rhetoric and social construction. London: Sage.

Potter, J. (1998). Discursive social psychology: From attitudes to evaluations, European Review of Social Psychology, 9, 233-266.

Potter, J. (2003). Discourse analysis and discursive psychology. In P. M. Camic, J. E. Rhodes, \& L. Yardley (Eds), Qualitative research in psychology: Expanding perspectives in methodology and design (pp. 73-94). Washington DC: American Psychological Association.

Potter, J. (in press). Discourse analysis. In M. Hardy \& A. Bryman (Eds), Handbook of Data Analysis. London: Sage.

Potter, J., \& Edwards, D. (2001). Discursive social psychology. In W. P. Robinson \& H. Giles (Eds.), The new handbook of language and social psychology (pp. 103-118). London: Wiley.

Potter, J., \& Edwards, D. (2003). Rethinking cognition: On Coulter, discourse and mind. Human Studies, 26, 165-181.

Potter, J., \& Wetherell, M. (1987). Discourse and social psychology: Beyond attitudes and behaviour. London: Sage. 
Potter, J., \& Wetherell, M. (1988). Accomplishing attitudes: Fact and evaluation in racist discourse. Text, 8(1-2), 51-68.

Shi-xu (2000). Opinion discourse: Investigating the paradoxical nature of the text and talk of opinions. Research on Language and Social Interaction, 33, 263-289.

Sparks, P., Conner, M., James, R., Shepherd, R., \& Povey, R. (2001). Ambivalence about healthrelated behaviours: An exploration in the domain of food choice. British Journal of Health Psychology, 6, 53-58.

Sparks, P., Hedderley, D., \& Shepherd, R. (1992). An investigation into the relationship between perceived control, attitude variability and the consumption of two common foods. European Journal of Social Psychology, 22, 55-71.

Thompson, M., Zanna, M., \& Griffin, D. (1995). 'Let's not be indifferent about (attitudinal) ambivalence'. In R. E. Petty \& J. A. Krosnick (Eds.), Attitude strength: Antecedents and consequences (pp. 361-386). Hillsdale, NJ: Erlbaum.

Verkuyten, M. (1998). Attitudes in public discourse: Speakers' own orientations. Journal of Language and Social Psychology, 17(3), 302-322.

Wetherell, M. (2001). Themes in discursive research: The case of Diana. In M. Wetherell, S. Taylor, \& S. J. Yates (Eds.), Discourse theory and practice: A reader (pp. 14-28). London: Sage.

Wetherell, M., \& Potter, J. (1992) Mapping the language of racism: Discourse and the legitimation of exploitation. Brighton: Harvester/Wheatsheaf.

Wiggins, S. (2001). Construction and action in food evaluation: Conversational data. Journal of Language and Social Psychology, 20(4), 445-463.

Wiggins, S., Potter, J., \& Wildsmith, A. (2001). Eating your words: Discursive psychology and the reconstruction of eating practices. Journal of Health Psychology, 6, 5-15.

Wiggins, S. (2002). Talking with your mouth full: Gustatory 'mmm's and the embodiment of pleasure. Research on Language and Social Interaction, 35(3): 311-336.

Wittgenstein, L. (1953). Philosophical investigations. Oxford: Blackwell.

Received 17 October 200I; revised version received 12 June 2002

\section{Appendix}

The detailed sections of transcript were transcribed using conventional Jefferson notation, as outlined below (see also Hutchby and Wooffitt, 1998, for a summary of these):

Don't Underlining indicates stress or emphasis in the speech.

(2.0) Numbers in brackets refer to pauses in tenths of a second. Those less than two-tenths of a second are indicated by (.).

(mine's) Words in brackets indicate the transcriber's best estimate of an unclear section of speech.

(h) Indicates laughter within speech

[ ] Square brackets indicate the beginning and end of overlapping talk.

$=\quad$ Equal signs indicate continuous talk between speakers.

- Degree signs enclose talk which is lower in volume than the surrounding talk.

$\uparrow \downarrow \quad$ Pointed arrows indicate a marked rising or falling in speech intonation.

$>\quad$ 'Greater than' and 'less than' signs enclose speech which is noticeably faster than the surrounding talk. When the order is reversed $(<>)$ this indicates slower speech.

? Question marks indicate a 'questioning' intonation, irrespective of grammar. 